\title{
Spark Plasma Sintering of Ultracapacitors
}

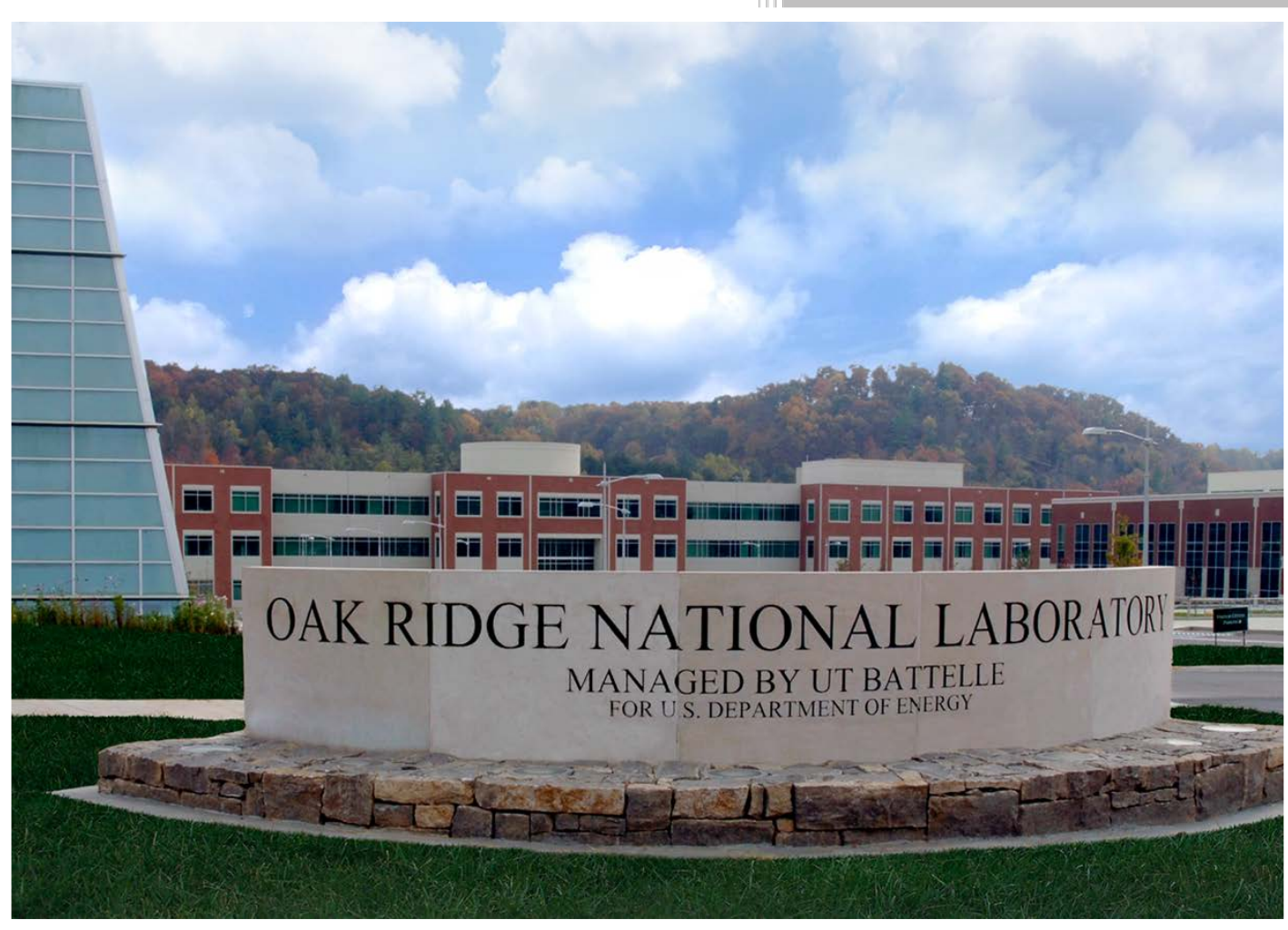

Curtis W. Hill

CK Technologies ORNL Dr. Lynn Boatner NASA Dr. Dennis Tucker ORNL J. A. Kolopus Auburn University Dr. Zhongyang Cheng 


\section{DOCUMENT AVAILABILITY}

Reports produced after January 1, 1996, are generally available free via US Department of Energy (DOE) SciTech Connect.

Website http://www.osti.gov/scitech/

Reports produced before January 1, 1996, may be purchased by members of the public from the following source:

National Technical Information Service

5285 Port Royal Road

Springfield, VA 22161

Telephone 703-605-6000 (1-800-553-6847)

TDD 703-487-4639

Fax 703-605-6900

E-mail info@ntis.gov

Website http://www.ntis.gov/help/ordermethods.aspx

Reports are available to DOE employees, DOE contractors, Energy Technology Data Exchange representatives, and International Nuclear Information System representatives from the following source:

Office of Scientific and Technical Information

PO Box 62

Oak Ridge, TN 37831

Telephone 865-576-8401

Fax 865-576-5728

E-mail reports@osti.gov

Website http://www.osti.gov/contact.html

This report was prepared as an account of work sponsored by an agency of the United States Government. Neither the United States Government nor any agency thereof, nor any of their employees, makes any warranty, express or implied, or assumes any legal liability or responsibility for the accuracy, completeness, or usefulness of any information, apparatus, product, or process disclosed, or represents that its use would not infringe privately owned rights. Reference herein to any specific commercial product, process, or service by trade name, trademark, manufacturer, or otherwise, does not necessarily constitute or imply its endorsement, recommendation, or favoring by the United States Government or any agency thereof. The views and opinions of authors expressed herein do not necessarily state or reflect those of the United States Government or any agency thereof. 


\title{
CK Technologies/NASA Marshall Flight Center
}

\section{Spark Plasma Sintering of Ultracapacitors}

\author{
Authors \\ CK Technologies Curtis W. Hill \\ ORNL Dr. Lynn Boatner \\ NASA Dr. Dennis Tucker \\ ORNL J. A. Kolopus \\ Auburn University Dr. Zhongyang Cheng
}

Date Published:

December 8, 2015

\author{
Prepared by \\ OAK RIDGE NATIONAL LABORATORY \\ Oak Ridge, Tennessee 37831-6283 \\ managed by \\ UT-BATTELLE, LLC \\ for the \\ US DEPARTMENT OF ENERGY \\ under contract DE-AC05-00OR22725
}

Approved for Public Release 


\section{CONTENTS}

Page

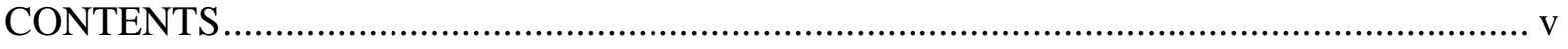

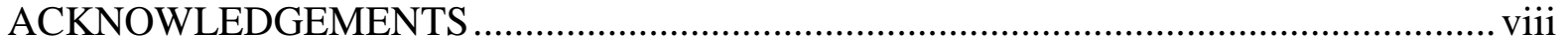

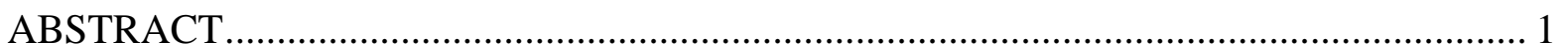

1. SPARK PLASMA SINTERING OF ULTRACAPACITORS ..................................... 1

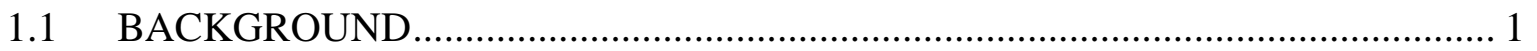

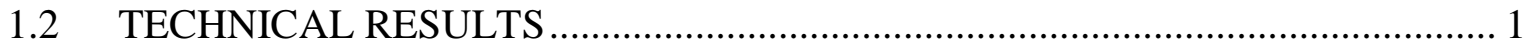

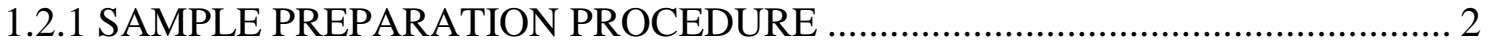

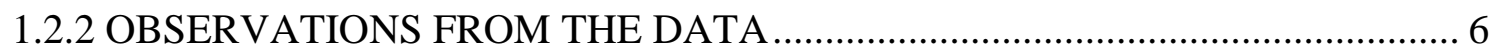

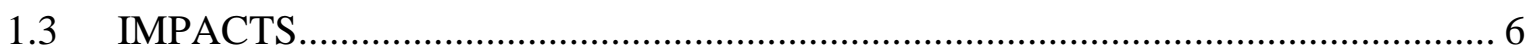

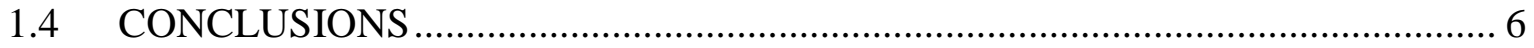

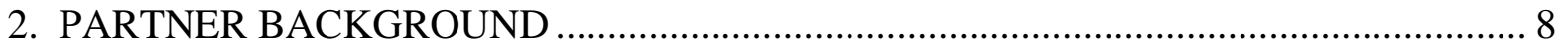




\section{TABLE OF FIGURES}

Fig. 1. ALD-coated barium titanate. .............................................................................. 2

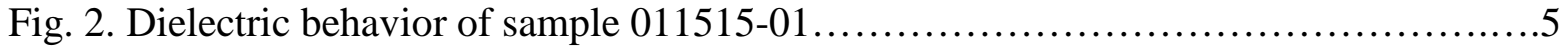

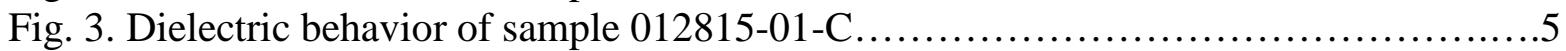

Fig. 4. Dielectric behavior of sample 031715-02-B............................... 5

Fig. 5. Dielectric behavior of sample 031815-01-A................................ 5 


\section{ACKNOWLEDGEMENTS}

This project was conducted as a Technical Collaboration project within the Oak Ridge National Laboratory (ORNL) Manufacturing Demonstration Facility (MDF) sponsored by the US Department of Energy Advanced Manufacturing Office (CPS Agreement Number 24761). Opportunities for MDF technical collaborations are listed in the announcement "Manufacturing Demonstration Facility Technology Collaborations for US Manufacturers in Advanced Manufacturing and Materials Technologies” posted at http://web.ornl.gov/sci/manufacturing/docs/FBO-ORNL-MDF-2013-2.pdf. The goal of technical collaborations is to engage industry partners to participate in short-term, collaborative projects within the Manufacturing Demonstration Facility (MDF) to assess applicability and of new energy efficient manufacturing technologies. Research sponsored by the U.S. Department of Energy, Office of Energy Efficiency and Renewable Energy, Advanced Manufacturing Office, under contract DE-AC05-00OR22725 with UT-Battelle, LLC. 



\begin{abstract}
A solid-state ultracapacitor module to replace standard electrochemical batteries would achieve major performance gains and mass/volume reduction. This report summarizes a project to evaluate an alternative sintering process to produce a solid-state ultracapacitor to overcome the limitations of both the electrochemical batteries presently in use on spacecraft and of currently available electrochemical ultracapacitors. It will provide a robust energy storage device with higher reliability, wider working temperature range, longer lifetime, and less weight and volume than electrochemical batteries. As modern electronics decrease in size, more efficient and robust remote power is needed. Current state-of-the-art rechargeable batteries cannot be rapidly charged, contain harmful chemicals, and suffer from early wearout mechanisms. Solid-state ultracapacitors are recyclable energy storage devices that offer the promise of higher power and a greater number of charge/discharge cycles than current rechargeable batteries. In addition, the theoretical energy density when compared to current electrochemical batteries indicates that a significant weight savings is possible. This is a project to develop a very high density solid-state ultracapacitor with giant permittivity and acceptable dielectric loss to overcome the energy-density barrier such that it will be a suitable replacement for batteries.
\end{abstract}

\title{
1. SPARK PLASMA SINTERING OF ULTRACAPACITORS
}

This Phase-1 technical collaboration project (MDF-TC-2013-023) began on September 24, 2013 and was completed on December 10, 2015. The collaborator, CK Technologies is a small business. Our team has achieved significant results on the fabrication of giant permittivity ultracapacitors, with some of the highest permittivities recorded anywhere in the literature. Further work is needed, however to balance these large permittivities with an acceptable dielectric loss.

\subsection{BACKGROUND}

The partner, CK Technologies, is a small business located in Huntsville, AL, working with NASA MFSC in the development of advanced materials and processes. As a result of our development of unique dielectric materials for the development of high-performance ultracapacitors, we identified Spark Plasma Sintering (SPS) as a potential technology to significantly enhance the density of the perovskite dielectric materials. ORNL has SPS capability, so we developed this partnership approach to evaluate this process for perovskite ceramic materials. This is a very new approach, with only a few investigations published, so we had to develop unique processes, material preparation, and testing methods to evaluate the SPS-sintered ceramics.

\subsection{TECHNICAL RESULTS}

Spark Plasma Sintering of perovskite ceramics materials is of interest due to the potential high density materials produced from the combination of high pressure, high current density, and high sintering temperatures. The recent work by the CNRS Institute in France has produced supercapacitors with very high permittivity using this method. ${ }^{1}$ Use of a rapid sintering method under reducing conditions leads to stable supercapacitor behavior. NASA has a need for ultracapacitors with high energy density. These sintered ceramic devices would also be very stable and would be safe in a spacecraft environment. The challenge with these devices is to produce high permittivity coupled with low dielectric loss. 
The technical approach to this project is to produce sintered dielectric devices from oxide-coated barium titanate perovskite ceramic powders. We have worked with industry experts in Atomic Layer Deposition (ALD) in order to coat various oxide materials with an extremely thin layer on nano-particles of $\mathrm{BaTiO}_{3}$. Once these coated particles are Spark Plasma Sintered (SPS), a barrier-layer is created with a semiconducting core of $\mathrm{BaTiO}_{3}$, with an insulating ALD coating. See figure 1 for an illustration of an ALDcoated particle.

We have evaluated several potential oxide materials for the ALD coating, including zirconia, alumina, and silica. We included zirconia and silica ALD-coated materials for the ORNL SPS study. Based on the initial results of the SPS runs and our prior experience with these coatings, we eliminated zirconia and concentrated on silica ALD coatings for most of the experimental runs.

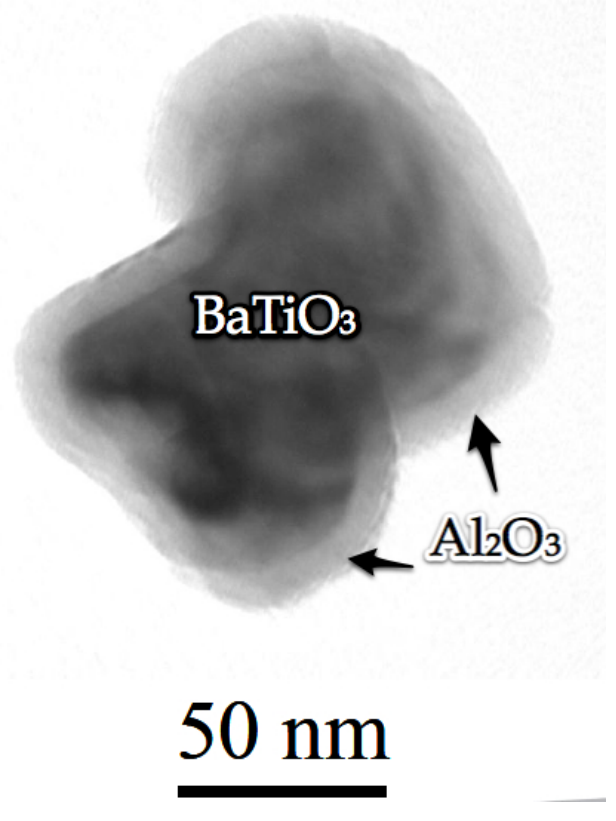

Fig. 1. ALD-coated barium titanate.

The sintering furnace used at ORNL was a Spark Plasma Sintering unit, model SPS-25-10, 25-ton force, 10,000 amp pulsed current power supply. The furnace was manufactured by Thermal Technology LLC of Santa Rosa, CA.

\subsubsection{Sample Preparation Procedure}

Spark Plasma Sintered samples of $\mathrm{SiO}_{2}$ coated Barium Titanate were prepared by ORNL from asreceived powder furnished by CK Technologies. A pre-determined amount of powder, typically from $5-9$ grams, was loaded into a high-density graphite die. The die measured $20 \mathrm{~mm}$ in diameter and was lined with 0.005 ” -thick Grafoil ${ }^{\mathrm{TM}}$ graphite paper. Several discs of Grafoil ${ }^{\mathrm{TM}}$ were also placed between the powder and the ends of the high-density graphite rams. Following the loading of the powder, the die assembly was placed into the SPS chamber and an initial force of 5 MPa was applied to the assembly. A total of 39 samples were processed over a 17-month period beginning in March of 2014 under the following range of conditions:

Heating rate:

Dwell Temperature:

$25^{\circ} \mathrm{C}-100^{\circ} \mathrm{C} /$ minute $1050^{\circ} \mathrm{C}-1200^{\circ} \mathrm{C}$ 
Dwell Time:

Cooling Rate:

In-situ Annealing Temperature:

In-situ Annealing Time:

Pressing Pressure:
30 seconds -5 minutes

$10^{\circ} \mathrm{C}-25^{\circ} \mathrm{C} /$ minute

$800^{\circ} \mathrm{C}-1050^{\circ} \mathrm{C}$

10 - 30 minutes

$25 \mathrm{MPa}-50 \mathrm{MPa}$

Following the sintering process, the samples were removed from the SPS chamber and extracted from the graphite die. As-pressed pellets generally measured from $4-7 \mathrm{~mm}$ in thickness. The resulting pellet was ground / cleaned with 600 grit silicon carbide paper to remove remnants of the graphite paper from the faces of the pellet. This cleaning process usually revealed numerous cracks within the body of the pellet and resulted in the separation of the pellet into multiple pieces as the graphite paper was removed. During the course of the material processing, numerous variations in the processing parameters were executed in an attempt to control or eliminate this cracking of the sample, however no consistent remedy was found for this condition. This will be an area of future investigation.

The resulting sample pieces were placed on an alumina ceramic tray and loaded into an electric resistance furnace for annealing in air at $800^{\circ} \mathrm{C}$ for 12 hours. Following annealing, the density of the finished sample was measured using a Sartorius Practium balance with an YDK03 Density Determination Kit and ethanol was used as the buoyant fluid.

Table 1 gives the details of the individual sintering runs and processing conditions, along with the testing results for each sample.

Several samples of particular interest from the runs are show in the following figures to illustrate the change in permittivity and dielectric loss with varying processing conditions.

Several samples showed very high permittivity or low dielectric loss at $1 \mathrm{kHz}$. These samples are summarized in Table 2, and additional charts showing their dielectric behavior are following as Figures 2-5. 
Table 1 - Sintering runs parameters and test results

\begin{tabular}{|c|c|c|c|c|c|c|c|c|c|c|c|c|c|c|c|c|}
\hline $\begin{array}{l}\text { Sample } \\
\quad \#\end{array}$ & Material & Temp. $\left({ }^{\circ} \mathrm{C}\right)$ & $\begin{array}{c}\text { Ramp } \\
\text { Rate } \\
\text { ('0/min) }\end{array}$ & $\begin{array}{l}\text { Dwell } \\
\text { (min. } \\
\text { ) }\end{array}$ & $\begin{array}{l}\text { Pressure } \\
(\mathrm{MPa})\end{array}$ & $\begin{array}{c}\text { Pressure } \\
\text { Ramp } \\
\text { Rate } \\
\text { (Mpa/min } \\
\text { ) }\end{array}$ & $\begin{array}{c}\text { Pressure } \\
\text { Dwell } \\
\text { (min.) }\end{array}$ & $\begin{array}{c}\text { Cooling } \\
\text { Ramp } \\
\left({ }^{\circ} \mathrm{C} / \mathrm{min}\right. \\
\quad)\end{array}$ & $\begin{array}{c}\text { Density } \\
\left(\mathrm{gm} / \mathrm{cm}^{3}\right)\end{array}$ & Area $\left(\mathrm{mm}^{2}\right)$ & $\begin{array}{l}\text { Thickness } \\
(\mathrm{mm})\end{array}$ & $\begin{array}{c}\mathcal{E}_{r} \\
\text { (at } 1 \mathrm{kHz})\end{array}$ & $\begin{array}{c}\tan \delta(\text { at } \\
1 \mathrm{kHz})\end{array}$ & $\begin{array}{l}\text { Freq. (at } \\
\text { min. loss) }\end{array}$ & $\begin{array}{l}\mathcal{E}_{r} \text { (at } \\
\text { min. } \\
\text { loss) }\end{array}$ & $\begin{array}{c}\text { Tand } \\
\text { (at min. } \\
\text { loss) }\end{array}$ \\
\hline $\begin{array}{c}011215 \\
-01\end{array}$ & $\begin{array}{c}9.0 \mathrm{~g} \\
\mathrm{BT} / \mathrm{SiO}_{2}\end{array}$ & $900 / 1125$ & $100 / 50$ & 3 & 50 & 10 & 0 & 40 & 5.838 & 310 & 3.52 & 856,536 & 1.777 & 22,427 & $\begin{array}{c}438,86 \\
9\end{array}$ & 0.573 \\
\hline $\begin{array}{c}011315 \\
-01\end{array}$ & $\begin{array}{c}7.33 \mathrm{~g} \\
\mathrm{BT} / \mathrm{SiO}_{2}\end{array}$ & $900 / 1075$ & $100 / 50$ & 3 & 50 & 10 & 0 & 40 & 5.804 & 165 & 3.72 & 529,577 & 2.294 & 23,591 & $\begin{array}{c}427,98 \\
2\end{array}$ & 0.318 \\
\hline $\begin{array}{c}011315 \\
-02\end{array}$ & $\begin{array}{c}8.0 \mathrm{~g} \\
\mathrm{BT} / \mathrm{SiO}_{2}\end{array}$ & $900 / 1100$ & $100 / 50$ & 3 & 50 & 10 & 0 & 40 & 5.895 & 150 & 3.98 & 846,779 & 1.691 & 18,315 & $\begin{array}{c}455,83 \\
0\end{array}$ & 0.515 \\
\hline \multirow[t]{4}{*}{$\begin{array}{c}011415 \\
-01\end{array}$} & \multirow[t]{4}{*}{$\begin{array}{c}5.8 \mathrm{~g} \\
\mathrm{BT} / \mathrm{SiO}_{2}\end{array}$} & \multirow[t]{4}{*}{$900 / 1150$} & \multirow[t]{4}{*}{$100 / 50$} & \multirow[t]{4}{*}{$\begin{array}{l}3 m / \\
2 m\end{array}$} & \multirow[t]{4}{*}{50} & \multirow[t]{4}{*}{10} & \multirow[t]{4}{*}{0} & \multirow[t]{4}{*}{40} & \multirow[t]{4}{*}{5.95} & 4.2 & 0.39 & 42,670 & 2.0208 & 41,209 & 30,446 & 0.248 \\
\hline & & & & & & & & & & 4.9 & 0.44 & 31,359 & 1.647 & 40,271 & 24,999 & 0.179 \\
\hline & & & & & & & & & & 10.5 & 0.65 & 52,081 & 0.165 & 2,187 & 48,761 & 0.152 \\
\hline & & & & & & & & & & 11 & 0.57 & 78,731 & 10.071 & 192,752 & 47,406 & 0.337 \\
\hline $\begin{array}{c}011515 \\
-01\end{array}$ & $\begin{array}{c}8.0 \mathrm{~g} \\
\mathrm{BT} / \mathrm{SiO}_{2}\end{array}$ & $900 / 1125$ & $100 / 50$ & $\begin{array}{l}2 m / \\
2 m\end{array}$ & 50 & 10 & 0 & 20 & 5.951 & 103 & 4.45 & $1,487,485$ & 3.222 & 53,039 & $\begin{array}{l}405,16 \\
5\end{array}$ & 0.919 \\
\hline \multirow[t]{2}{*}{$\begin{array}{c}012815 \\
-01\end{array}$} & \multirow[t]{2}{*}{$\begin{array}{c}8.6 \mathrm{~g} \\
\mathrm{BT} / \mathrm{SiO}_{2}\end{array}$} & \multirow[t]{2}{*}{$\begin{array}{c}750 / 1000 / 110 \\
0\end{array}$} & \multirow[t]{2}{*}{$\begin{array}{c}75 / 50 / 2 \\
5\end{array}$} & \multirow[t]{2}{*}{0.5} & \multirow[t]{2}{*}{50} & \multirow[t]{2}{*}{10} & \multirow[t]{2}{*}{0} & \multirow[t]{2}{*}{20} & \multirow[t]{2}{*}{5.949} & 27 & 0.89 & 163,815 & 1.413 & 39,810 & $\begin{array}{c}109,06 \\
8\end{array}$ & 0.208 \\
\hline & & & & & & & & & & 26.5 & 0.9 & 313,623 & 0.991 & 64,565 & $\begin{array}{c}105,48 \\
8\end{array}$ & 0.288 \\
\hline \multirow[t]{2}{*}{$\begin{array}{c}020715 \\
-01\end{array}$} & \multirow[t]{2}{*}{$\begin{array}{c}10.2 \mathrm{~g} \\
\mathrm{BT} / \mathrm{SiO}_{2}\end{array}$} & \multirow[t]{2}{*}{$\begin{array}{c}750 / 1000 / 110 \\
0\end{array}$} & \multirow[t]{2}{*}{$\begin{array}{c}75 / 50 / 2 \\
5\end{array}$} & \multirow[t]{2}{*}{0.5} & \multirow[t]{2}{*}{50} & \multirow[t]{2}{*}{10} & \multirow[t]{2}{*}{0} & \multirow[t]{2}{*}{20} & \multirow[t]{2}{*}{5.902} & 14.2 & 0.62 & 132,315 & 3.799 & 104,713 & 63,959 & 0.362 \\
\hline & & & & & & & & & & 21.5 & 0.64 & 95,121 & 0.324 & 35,481 & 66,355 & 0.147 \\
\hline $\begin{array}{c}021415 \\
-01\end{array}$ & $\begin{array}{c}11.0 \mathrm{~g} \\
\mathrm{BT} / \mathrm{SiO}_{2}\end{array}$ & $\begin{array}{c}750 / 1000 / 107 \\
0\end{array}$ & $\begin{array}{c}75 / 50 / 2 \\
5\end{array}$ & 0.5 & 50 & 10 & 0 & 10 & 5.725 & & & & & & & \\
\hline $\begin{array}{c}031715 \\
-02\end{array}$ & $\begin{array}{c}11.0 \mathrm{~g} \\
\mathrm{BT} / \mathrm{SiO}_{2}\end{array}$ & $1000 / 1100$ & 25 & 2 & 50 & 10 & 0 & $5 / 10$ & 5.835 & 16.5 & 0.97 & 28,718 & 110.25 & $\begin{array}{c}1,000,00 \\
0 \\
\end{array}$ & 2,235 & 2.702 \\
\hline & & & & & & & & & & 65.2 & 0.53 & 420,987 & 0.738 & 1,634 & $\begin{array}{c}356,13 \\
0\end{array}$ & 0.723 \\
\hline $\begin{array}{c}031715 \\
-01\end{array}$ & $\begin{array}{c}5.0 \mathrm{~g} \\
\mathrm{BT} / \mathrm{SiO}_{2}\end{array}$ & 1080 & 25 & 1 & 50 & 10 & 0 & $7 / 10$ & 5.896 & 11.4 & 0.42 & 71,829 & 0.284 & 5,412 & 58,756 & 0.239 \\
\hline $\begin{array}{c}031815 \\
-02\end{array}$ & $\begin{array}{c}8.16 \mathrm{~g} \\
\mathrm{BT} / \mathrm{SiO}_{2}\end{array}$ & 1100 & 50 & 0.5 & 25 & 10 & 0 & 20 & 5.783 & 19.6 & 0.73 & 273,681 & 10.17 & 45,012 & 81,238 & 1.484 \\
\hline & & & & & & & & & & 18.8 & 1.12 & 385,857 & 3.916 & 14,017 & $\begin{array}{c}243,95 \\
5\end{array}$ & 0.922 \\
\hline $\begin{array}{c}031815 \\
-01\end{array}$ & $\begin{array}{c}7.0 \mathrm{~g} \\
\mathrm{BT} / \mathrm{SiO}_{2}\end{array}$ & 1100 & 50 & 0.5 & 30 & 10 & 0 & 20 & 5.937 & 21 & 0.9 & 448,504 & 0.755 & 25,902 & $\begin{array}{c}165,49 \\
0\end{array}$ & 0.432 \\
\hline & & & & & & & & & & 16.3 & 0.35 & 126,620 & 0.652 & 9,120 & 82,395 & 0.405 \\
\hline & & & & & & & & & & 20.2 & 0.4 & 116,770 & 0.652 & 8,066 & 77,894 & 0.405 \\
\hline
\end{tabular}


Table 2 - Samples with high permittivity or low dielectric loss

\begin{tabular}{|c|c|c|c|c|c|c|c|c|l|}
\hline Figure & Sample \# & $\begin{array}{c}\varepsilon_{r} \\
\text { (at 1 } \\
\mathrm{kHz})\end{array}$ & $\begin{array}{c}\text { tan } \delta \\
\text { (at 1 } \\
\mathrm{kHz})\end{array}$ & $\begin{array}{c}\text { Temp. } \\
{ }^{\circ} \mathrm{C}\end{array}$ & $\begin{array}{c}\text { Dwell } \\
(\mathrm{min} .)\end{array}$ & $\begin{array}{c}\text { Pressure } \\
\text { Mpa }\end{array}$ & $\begin{array}{c}\text { Cooling } \\
\text { Ramp } \\
\text { Rate } \\
\left({ }^{\circ} \mathrm{C} / \mathrm{min}\right)\end{array}$ & $\begin{array}{c}\text { Density } \\
\left(\mathrm{gm} / \mathrm{cm}^{3}\right)\end{array}$ & Comments \\
\hline 2 & $011515-01$ & $1,487,485$ & 3.222 & 1,125 & 2 & 50 & 20 & 5.951 & dark blue color \\
\hline 3 & $012815-01$ & 1,945 & 0.072 & 1,100 & 0.50 & 50 & 20 & 5.949 & bluish white color \\
\hline 4 & $031715-02$ & 420,987 & 0.738 & 1,100 & 2 & 50 & 10 & 5.835 & dark blue color \\
\hline 5 & $031815-01$ & 448,504 & 0.755 & 1,100 & 1 & 30 & 20 & 5.937 & dark blue color \\
\hline
\end{tabular}

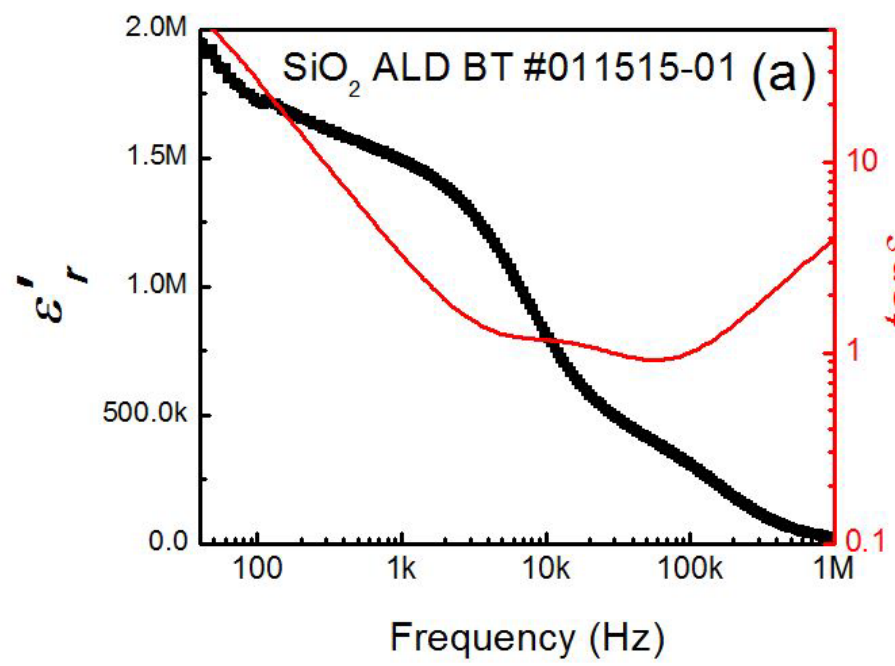

Fig 2. Dielectric behavior of sample 011515-01.

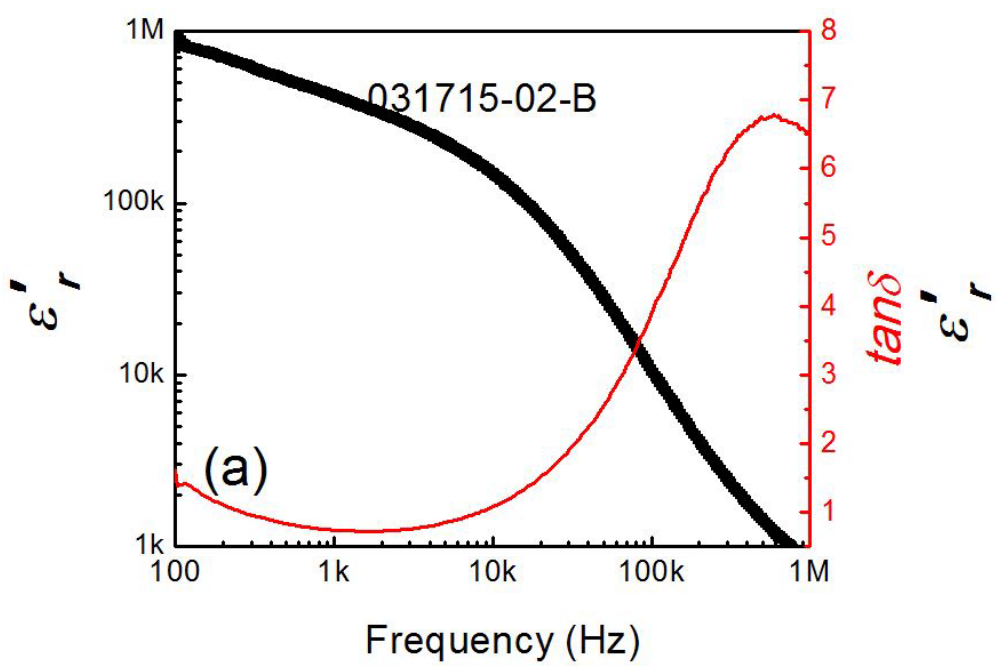

Fig 4. Dielectric behavior of sample 031715-02-B.

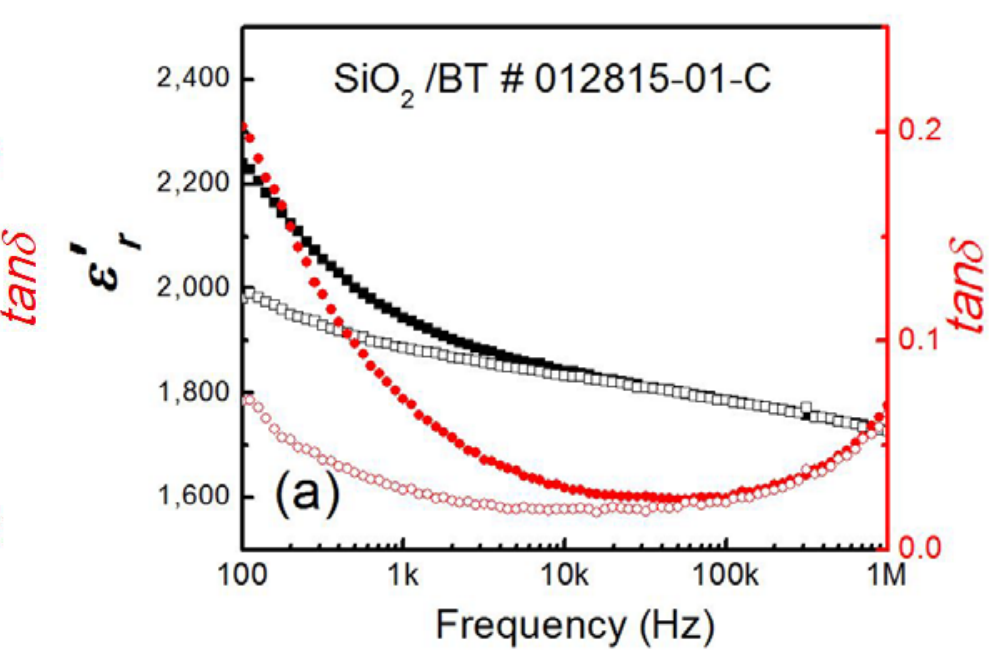

Fig 3. Dielectric behavior of sample 012815-01-C.

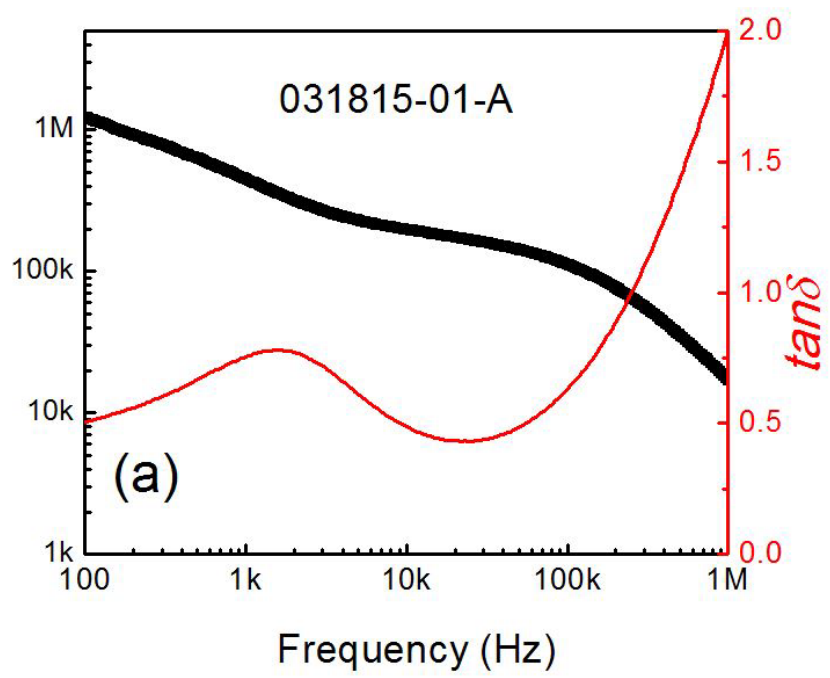

Fig 5. Dielectric behavior of sample 031815-01-A. 


\subsubsection{Observations from the data}

The observation of permittivity values over 1,500,000 is an extraordinary finding for dielectric materials, and it makes the extended investigation and optimization of the SPS sintering method of significance. We observed that these gigantic permittivities were somewhat consistent with the highest densities of the samples measured, and we further observed that these samples exhibited a dark navy blue color due to Ti reduction.

However, the dielectric losses for these very dense samples were unacceptably high. We observed improved overall dielectric behavior and lower loss for samples with somewhat lower densities. In addition, these samples were observed to exhibit a pale blue-gray color, and they showed much better dielectric loss values. We are seeking to better understand the grain-boundary effects on both the high permittivity and the low-loss samples. We will be working in the near future with the ORNL User Facility for carrying out detailed studies of these effects. (See more information below in the Conclusions.)

Future research will be focused on "tuning" the sintering process parameters to produce pristine, unbroken, sintered devices and to balance out the observed properties to produce the desired gigantic permittivity and still exhibit acceptable dielectric loss. It may also be possible to research different thickness coatings and different materials for the coatings to further optimize the final dielectric properties of the sintered samples.

\subsection{IMPACTS}

This study represents a substantial start in the area of advanced research on sintering dielectric materials with Spark Plasma Sintering methods. We have now gained a better understanding of the sintering process and variations in the material preparation that will guide our future investigations.

The potential impact of this research lies in the ability to produce dielectric material with gigantic permittivity for a number of applications, including energy storage, propulsion, and many others. This material would also be very stable, could be used in a wide range of temperature environments, and would be extremely safe compared with existing electrochemical technologies for dielectric materials.

This sintering method would potentially become a reliable commercial fabrication method for producing safe, reliable dielectric materials for a wide range of both terrestrial and space technology applications.

\subsection{CONCLUSIONS}

As noted previously, this research project is a significant start on investigating spark plasma sintering as a method of producing very high permittivity dielectric materials. However, there is much work to still be done in the areas of refining the process parameters, determine effects that these parameters have on dielectric behavior, and explaining the grain boundary mechanics at the atomic level to enhance future research and development progress.

To this end, CK Technologies, NASA, and Auburn University submitted a User Facility Research Proposal to ORNL to examine the dielectric materials produced from this study and to determine these grain boundary mechanisms. This work will be performed with Dr. Karren More at the Nanoscience Research Program at the Center for Nanophase Materials Sciences (CNMS). This work, proposal CNMS2015-214 Project Title: Characterization of nanostructured ceramics prepared using Spark Plasma Sintering for electric energy storage, will be performed in December 2015 and January 2016 for the preliminary stages of investigation. 
In addition, the partner, with NASA Marshall Space Flight Center, has obtained funding for the purchase of a Direct Current Sintering (DCS) furnace to be located in Huntsville, AL at MSFC. This furnace will allow rapid sintering of the ceramic ultracapacitor samples, without power transients, which are common with the Spark Plasma Sintering furnaces. The follow-up research to this project will be conducted in FY16 and beyond on high-performance sintered dielectric materials, as well as advanced solid state thermoelectric materials using the same process researched in the project.

The research findings on optimum processing and sample preparation that were obtained from this study will be utilized in future DCS sintering research. 


\section{PARTNER BACKGROUND}

CK Technologies is a small business located in Huntsville, AL. CK Technologies supports NASA Marshall Space Flight Center and AMRDEC in advanced manufacturing processes and materials, as well as materials development for NASA development in energy storage, thermoelectric materials, and 3D embedded electronics development for the International Space Station.

1 “Controlling internal barrier in low loss BaTiO3 supercapacitors, Chung, Elissalde, Mornet, and Maglione. 